\title{
Using adult Aedes aegypti females to predict areas at risk for dengue transmission: A spatial case-control study
}

\author{
Maisa Carla Pereira Parra ${ }^{\mathrm{a}}$, Eliane Aparecida Fávaro ${ }^{\mathrm{a}}$, Margareth Regina Dibo ${ }^{\mathrm{b}}$, \\ Adriano Mondini ${ }^{\mathrm{c}}$, Álvaro Eduardo Eiras ${ }^{\mathrm{d}}$, Erna Geessien Kroon ${ }^{\mathrm{e}}$, Mauro Martins Teixeira ${ }^{\mathrm{f}}$, \\ Mauricio Lacerda Nogueira ${ }^{a}$, Francisco Chiaravalloti-Neto ${ }^{\text {g,* }}$ \\ ${ }^{a}$ Laboratório de Pesquisa em Virologia, Faculdade de Medicina de São José do Rio Preto, Avenida Brigadeiro Faria Lima 5416, São José do Rio Preto, SP, Brazil \\ ${ }^{\mathrm{b}}$ Laboratório de Entomologia, Superintendência de Controle de Endemias, Rua Cardeal Arcoverde 2878, 05408003, São Paulo, SP, Brazil \\ ${ }^{\mathrm{c}}$ Laboratório de Saúde Pública, Faculdade de Ciências Farmacêuticas, Campus Araraquara, Universidade Estadual Paulista (UNESP), Rodovia Araraquara-Jaú km 1, \\ Araraquara, SP, Brazil \\ d Departamento de Parasitologia, Instituto de Ciências Biológicas, Universidade Federal de Minas Gerais, Avenida Antônio Carlos 6627, Belo Horizonte, MG, Brazil \\ e Departamento de Bioquímica e Imunologia, Instituto de Ciências Biológicas, Universidade Federal de Minas Gerais, Avenida Antônio Carlos 6627, Belo Horizonte, MG, \\ Brazil \\ ${ }^{\mathrm{f}}$ Departamento de Microbiologia, Instituto de Ciências Biológicas, Universidade Federal de Minas Gerais, Avenida Antônio Carlos 6627, Belo Horizonte, MG, Brazil \\ ${ }^{8}$ Departamento de Epidemiologia, Faculdade de Saúde Pública, Universidade de São Paulo, Avenida Doutor Arnaldo 715, São Paulo, SP, Brazil
}

\section{A R T I C L E I N F O}

\section{Keywords:}

Dengue virus

Entomological index

Aedes aegypti

Spatial analysis

\begin{abstract}
A B S T R A C T
Introduction: Traditional indices for measuring dengue fever risk in a given area are based on the immature forms of the vector (larvae and pupae surveys). However, this is inefficient because only adult female mosquitoes actually transmit the virus. Based on these assumptions, our objective was to evaluate the association between an entomological index obtained from adult mosquito traps and the occurrence of dengue in a hyperendemic area. Additionally, we compared its cost to that of the Breteau Index (BI).

Material and methods: We performed this study in São José do Rio Preto, SP, Brazil, between the epidemiological weeks of 36/2012 and 19/2013. BG-Sentinel and BG-Mosquitito traps were installed to capture adult mosquitoes. Positive and negative cases of dengue fever were computed and geocoded. We generated biweekly thematic maps of the entomological index, generated by calculating the number of adult Aedes aegypti females (NAF) per 100 households during a week by kriging, and based on the number of mosquitoes captured. The relation between the occurrence of dengue fever and the NAF was tested using a spatial case-control design and a generalized additive model and was controlled by the coordinates of the positive and negative cases of dengue fever.

Results: Our analyses showed that increases in dengue fever cases occurred in parallel with increases in the number of Ae. aegypti females. The entomological index produced in our study correlates positively with the incidence of dengue, particularly during intervals when vector control measures were applied less intensively. The operational costs of our index were lower than those of the BI: NAF used $71.5 \%$ less human resources necessary to measure the BI.

Conclusions: Spatial analysis techniques and the number of adult Ae. aegypti females were used to produce an indicator of dengue risk. The index can be applied at various levels of spatial aggregation for an entire study area, as well as for sub-areas, such as city blocks. Even though the index is adequate to predict dengue risk, it should be tested and validated in various scenarios before routine use.
\end{abstract}

\section{Introduction}

Dengue causes serious health problems worldwide, with nearly 390 million infections every year (WHO, 2009). According to the Brazilian Ministry of Health (MS, 2016), there were almost 1.5 million cases of dengue fever in 2015. During the same period, the state of São Paulo

\footnotetext{
* Corresponding author at: Faculdade de Saúde Pública da Universidade de São Paulo, Avenida Doutor Arnaldo, 715, São Paulo, SP, CEP 01246904, Brazil.

E-mail addresses: maisapparra@hotmail.com (M.C.P. Parra), eliane_favaro@yahoo.com.br (E.A. Fávaro), medibo@sucen.sp.gov.br (M.R. Dibo), amondini@fcfar.unesp.br (A. Mondini), alvaro@icb.ufmg.br (Á.E. Eiras), kroone@icb.ufmg.br (E.G. Kroon), mmtex@icb.ufmg.br (M.M. Teixeira), mnogueira@famerp.br (M.L. Nogueira), franciscochiara@usp.br (F. Chiaravalloti-Neto).
} 
reported over 700,000 cases, and the city of São José do Rio Preto reported over 27,000 suspected cases (CVE, 2016; SVS, 2017). In 2017, more than 81,000 dengue cases were reported in São Paulo state and São José do Rio Preto reported 3205 suspect dengue cases (CVE, 2018). Dengue fever is caused by an arbovirus belonging to the Flavivirus genus and it is classified into four serotypes, DENV 1-4 (WHO, 2009).

In Brazil, DENV is transmitted to humans through the bite of infected females of Aedes aegypti mosquitos (Campbell et al., 2015; Zayed et al., 2012). This species is found throughout the country, particularly in urban areas, because of its synanthropic behavior. Ae. aegypti is found both inside and around households. The mosquito reproduces in artificial containers of still, clean water, preferably without organic matter (Coelho, 2012; Lau et al., 2013; MS, 2014; Reiter et al., 1995). It is also implicated in transmission of zika and chikungunya viruses, both of which have led to a series of outbreaks throughout American continents. Zika is associated with neurological abnormalities and cases of microcephaly in newborns (Estofolete et al., 2016), while chikungunya has been associated with chronic arthritis (Chen and Wilson, 2010).

Entomological surveillance and vector control, as well as infection monitoring, are currently the only tools available to contain the spread of these diseases. The most common indices to measure infestation by Ae. aegypti mosquitos are the Stegomyia indices, which are based on immature forms of the vector (larvae and pupae). For this reason, Breteau Index (BI), house index, and container index, supply no information regarding the productivity of adult mosquitos (Barrera, 2016; Bowman et al., 2014; Focks et al., 2000; Focks, 2004; Gomes, 1998; Higa, 2011). There are still questions concerning the ability of these indices to estimate the real risk of arbovirus infections.

The use of traps to capture adult female mosquitoes presents a viable alternative for monitoring vector infestation. These traps can generate information about the stages of life of the mosquitoes that are closest to transmit a virus. Consequently, traps can generate entomological indices more accurately, and estimate the risk of dengue, zika, and chikungunya transmission with greater precision (Barrera, 2016; Steffler et al., 2011). These traps are as effective as human bait collection, and are more effective than manual aspirators (Figueiredo et al., 2013; Hapairai et al., 2013; Maciel-de-Freitas et al., 2006, 2008). Other tools to detect high-risk clusters in a given area are Geographical Information Systems (GISs) and spatial analysis techniques, as demonstrated by Barbosa et al. (2014) and Chiaravalloti-Neto et al. (2015).

In light of these issues, the objective of this study was to evaluate the association between an entomological index obtained from adult mosquito traps and the occurrence of dengue in a hyperendemic area. In addition, we compared the cost of human resources required to obtain our index to the cost of obtaining the Breteau Index. Our hypothesis is that this new index provides a measurement of entomological surveillance that is capable of efficiently and accurately predicting the risk of dengue at various levels of spatial aggregation.

\section{Materials and methods}

\subsection{Study area and timeframe}

São José do Rio Preto is a city located in the northeastern region of the state of São Paulo, Brazil ( $20^{\circ} 49^{\prime} 11^{\prime \prime}$ S and $49^{\circ} 22^{\prime} 46^{\prime \prime}$ W). In 2015, it had a population of 442,548 people (IBGE, 2017). The climate is tropical, with an average temperature of $25^{\circ} \mathrm{C}$, and a yearly average rainfall of $1410 \mathrm{~mm}$. The altitude is $475 \mathrm{~m}$ above sea level (CPTEC, 2015). We chose the neighborhood of Solo Sagrado (with 25,000 residents in 7800 households spread over 227.8 ha), because this area experiences frequent cases of dengue (Fig. 1).

Ae. aegypti mosquito species was introduced in the city in 1985, and the first autochthonous case of dengue (DENV-1) was confirmed in 1990. DENV-2, DENV-3, and DENV-4 were detected in 1998, 2005, and 2011, respectively (Mondini et al., 2009; Rocco et al., 2012). Colombo et al. (2013) reported the first case of DENV-4 in 2011, simultaneously with the public health authority of the State, which detected this serotype in the same patient. In 2011, DENV-4 was detected co-circulating with the DENV-1 and DENV-2 (Souza et al., 2011), and caused major outbreaks in the next two years.

In order to define the timeframe of the study as being from September 2012 to May 2013 (between epidemiological weeks 36/ 2012 and 19/2013), we considered the distribution of reported and confirmed dengue cases in São José do Rio Preto from 2009 to 2015 (Fig. 2). There was a seasonal pattern of disease occurrence, with lower and higher incidences occurring respectively in August and September and March and April (CVE, 2016). It is important to mention that this study was performed after the introduction of DENV-4 into the city.

\subsection{Trap installation and mosquito capture}

To capture adult mosquitoes, we used 31 traps produced by Biogents (six BG-Sentinel ${ }^{\mathrm{TM}}$ (Biogents BGS) and 25 BG-Mosquitito $^{\mathrm{TM}}$ (Biogents AG)). According to the manufacturer, both traps capture mosquitoes with similar efficiency. These traps were installed twice a week, allowing us to gather data up to 62 houses per week. Since we had only six BG-Sentinel and 25 BG-Mosquitito to perform our study, and considering they have similar efficiency, we chose to use them to increase the number of houses with traps and to minimize operational problems, such as closed properties, refusal of resident, changes of the resident address, days off, among other reasons.

Taking into account that $A$ e. aegypti female flight radius, which can reach up to $800 \mathrm{~m}$, usually does not exceed 150-200 m (Forattini, 2002; Honório et al., 2003; Reiter et al., 1995), we considered that the maximum distance between two traps should not exceeded $400 \mathrm{~m}$ (two times the flight radius). With 62 houses with traps per week, the average distance between two traps would be $192 \mathrm{~m}$ (the square root of the division of the study area by the number of houses), which is less than maximum distance we fixed. We also had a safety margin for any operational problems that could occur. Traps were installed near plant pots, with no direct exposition to sun and rain in preselected residences with shaded areas.

Traps were installed weekly between epidemiological weeks 36/ 2012 and 19/2013 in the preselected households whenever possible. There were, however, changes in trap locations when the homeowner no longer approved the installation or relocated to another residence. In such cases, we set up the trap in a household within the same block, and as close as possible of the pre-selected premise.

Traps were installed on Mondays and Thursdays and collected respectively on Tuesdays and Fridays. They were maintained at each residence for $24 \mathrm{~h}$. It would not be feasible to install traps every day to measure variations in the daily number of mosquitoes during a week, mostly due to technical difficulties such as size of the neighborhood and number of personnel to install and collect traps. However, our schedule provided a reasonable representation of adult infestation levels in four days of the week, since traps collected mosquitos in different periods of Monday/Thursday and Tuesday/Friday, respectively installation and collection days.

Mosquitos collected from traps were identified at the Laboratory of Entomology with specific taxonomic keys (Consoli and Oliveira, 1994; Forattini, 2002). Specimens were pooled in tubes with up to 10 mosquitoes of the same species, gender, site and date of collection, and type of trap. Pools were stored at $-80^{\circ} \mathrm{C}$ until molecular analysis.

\subsection{Molecular analysis}

The molecular analysis was performed only on Ae. aegypti pools. RNA extraction was performed according to Machado et al. (2012). Briefly, $50 \mu \mathrm{l}$ of PBS $1 \mathrm{X}$ were added to the mosquito pool for initial maceration with autoclaved polypropylene pistil, followed by the addition of $850 \mu \mathrm{l}$ of PBS 1X to homogenize the macerate. The pool was centrifuged for $4 \mathrm{~min}$ at $2300 \mathrm{~g}$ in a refrigerated centrifuge $\left(4^{\circ} \mathrm{C}\right)$. An 


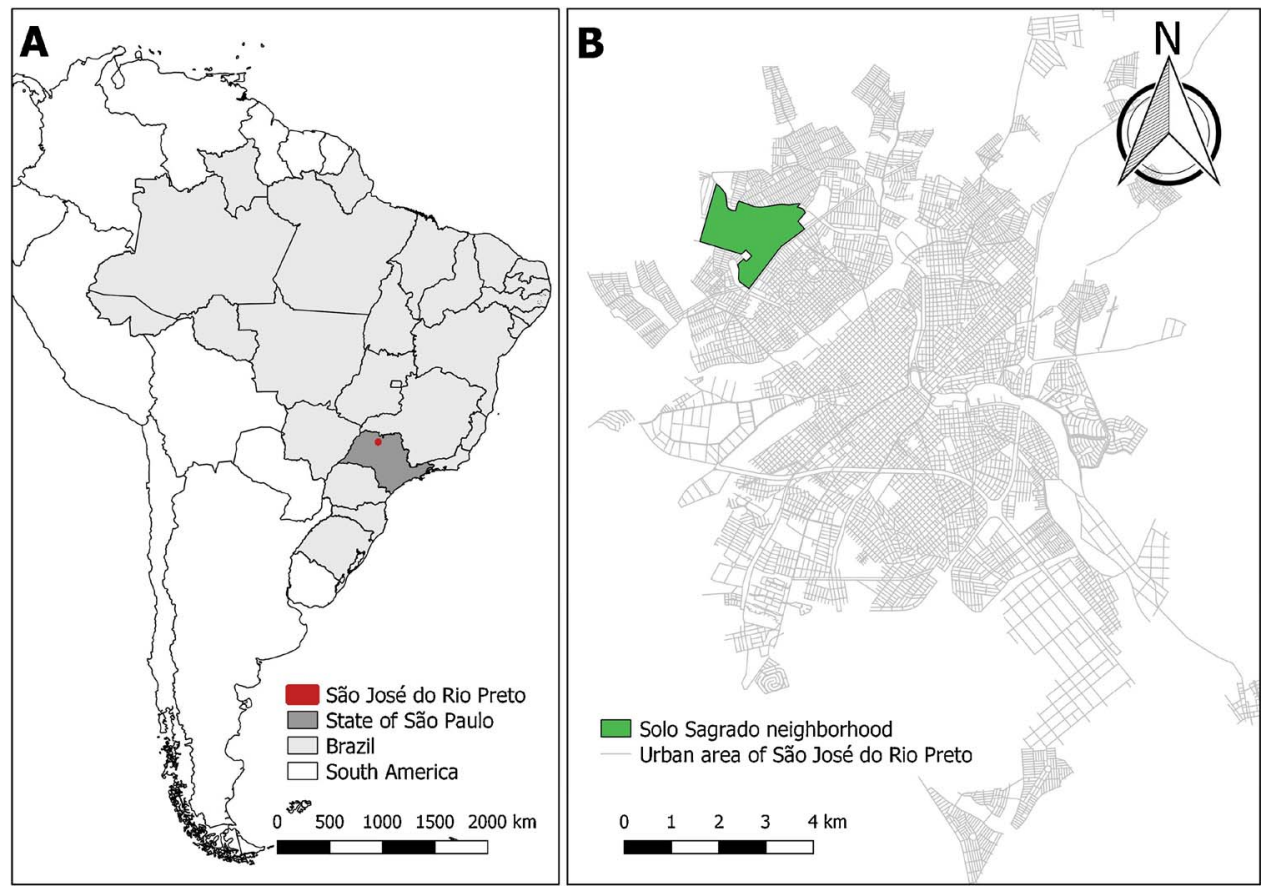

Fig. 1. (A) South America, Brazil, state of São Paulo and the city of São José do Rio Preto; (B) The urban area of the city of São José do Rio Preto and, in green, the study area: the Solo Sagrado neighborhood. This figure was produced by the authors with data that is available to be free downloaded from Instituto Brasileiro de Geografia e Estatística - IBGE (2017), a public organization of the Brazilian government that provides statistical and geoscience information. (For interpretation of the references to colour in this figure legend, the reader is referred to the web version of this article.)

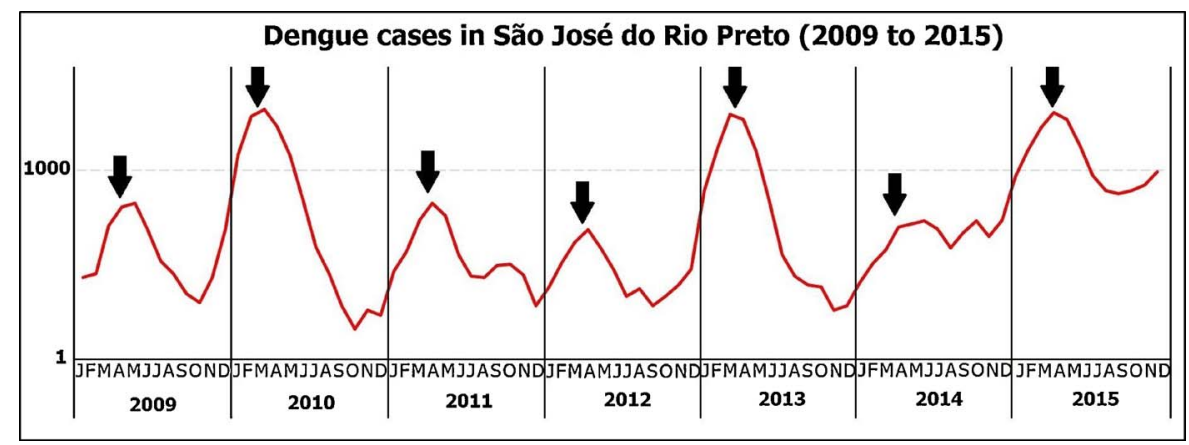

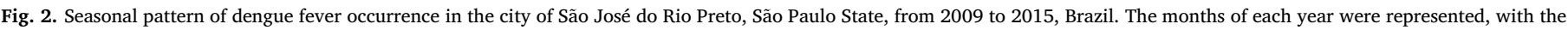
arrow indicating months with the highest incidences (months of March and April).

aliquot of $100 \mu \mathrm{l}$ was used for viral RNA extraction and the remainder was stored at $-80^{\circ} \mathrm{C}$. Next, we added $400 \mu \mathrm{l}$ of Trizol (Life Technologies - USA) and $200 \mu \mathrm{l}$ of chloroform, mixing the solution 30 times by inversion. The mix was incubated at room temperature for $3 \mathrm{~min}$ and then centrifuged at $9300 \mathrm{~g}$ for $15 \mathrm{~min}$ at $4{ }^{\circ} \mathrm{C}$. The clear upper aqueous layer containing total RNA was recovered and transferred to a new $1500 \mu \mathrm{l}$ polypropylene tube, with $500 \mu \mathrm{l}$ of 2 -propanol to precipitate the RNA. This solution was mixed 30 times by inversion, incubated for $10 \mathrm{~min}$ at room temperature and centrifuged at $9300 \mathrm{~g}$ for $15 \mathrm{~min}$ at $4{ }^{\circ} \mathrm{C}$. The supernatant was removed and the pellet was washed with $1000 \mu \mathrm{l} 75 \%$ ethanol and centrifuged at $3300 \mathrm{~g}$ at $4{ }^{\circ} \mathrm{C}$ for $5 \mathrm{~min}$. The supernatant was discarded and the RNA pellets were air dried at room temperature and re-suspend in $30 \mu \mathrm{l}$ of RNAse-free water and used for downstream application or stored at $-80^{\circ} \mathrm{C}$.

The reverse transcriptase mixture contained $8 \mu$ of RNA template, $4 \mu \mathrm{l}$ of $5 \times$ first strand buffer ( $250 \mathrm{mM}$ Tris- $\mathrm{HCl}$ [pH 8.3], $375 \mathrm{mM} \mathrm{KCl}$, $15 \mathrm{mM} \mathrm{MgCl} 2), 1.5 \mu \mathrm{l}$ of dithiothreitol $(0.1 \mathrm{M}), 1 \mu \mathrm{l}$ of the genus-specific reverse primer FG2 $(15 \mu \mathrm{M}), 1 \mu \mathrm{l}$ of Deoxynucleotide triphosphate (dNTP) mixture ( $250 \mu \mathrm{M}$ each dNTP), $20 \mathrm{U}$ of RNase inhibitor (RNase OUT; Invitrogen), $200 \mathrm{U}$ of reverse transcriptase (Superscript III Reverse Transcriptase; Invitrogen), and water for a final volume of $20 \mu \mathrm{l}$. The mixture was incubated at $42^{\circ} \mathrm{C}$ for $50 \mathrm{~min}$ followed by $95^{\circ} \mathrm{C}$ for $5 \mathrm{~min}$ to inactivate the reverse transcriptase. The initial PCR mixture contained $8 \mu \mathrm{l}$ of cDNA, $5 \mu \mathrm{l}$ of $10 \mathrm{x}$ PCR buffer $(200 \mathrm{mM}$ Tris- $\mathrm{HCl}[\mathrm{pH}$
8.4], $500 \mathrm{mM} \mathrm{KCl}), 2 \mu \mathrm{l}$ of $\mathrm{MgCl} 2(50 \mathrm{mM}), 1 \mu \mathrm{l}$ of dNTP mixture (250 $\mu \mathrm{M}$ each dNTP), $1 \mathrm{U}$ of Taq DNA polymerase (Platinum Taq DNA polymerase; Invitrogen), $1 \mu \mathrm{l}$ of the forward genus-specific primer FG1 $(15 \mu \mathrm{M})$, and water for a final volume of $50 \mu \mathrm{l}$. Amplification occurred in 30 cycles of $94^{\circ} \mathrm{C}$ for $1 \mathrm{~min}, 53^{\circ} \mathrm{C}$ for $1 \mathrm{~min}$, and $72^{\circ} \mathrm{C}$ for $2 \mathrm{~min}$, followed by a final extension step at $72{ }^{\circ} \mathrm{C}$ for $5 \mathrm{~min}$. The second amplification reaction mixture contained $1 \mu$ of the first amplification reaction, $5 \mu \mathrm{l}$ of PCR buffer ( $200 \mathrm{mM}$ Tris- $\mathrm{HCl}$ [pH 8.4], $500 \mathrm{mM} \mathrm{KCl}$ ), $2 \mu \mathrm{l}$ of $\mathrm{MgCl} 2(50 \mathrm{mM}), 1 \mu \mathrm{l}$ of dNTP mixture ( $250 \mu \mathrm{M}$ each dNTP), $1 \mathrm{U}$ of Taq DNA polymerase (Platinum Taq DNA polymerase; Invitrogen) $1 \mu \mathrm{l}$ of genus-specific forward primer FG1 $(15 \mu \mathrm{M})$ and reverse inner species specific primers $(15 \mu \mathrm{M})$ for DENV 1 , DENV 2, DENV 3, DENV-4 and water for a final volume of $50 \mu$. The mixture was subjected to 25 cycles of $94^{\circ} \mathrm{C}$ for $1 \mathrm{~min}, 53^{\circ} \mathrm{C}$ for $1 \mathrm{~min}$, and $72{ }^{\circ} \mathrm{C}$ for $2 \mathrm{~min}$. A final extension step was carried out at $72{ }^{\circ} \mathrm{C}$ for $5 \mathrm{~min}$. The amplicons were submitted to electrophoresis in an $8 \%$ polyacrylamide gel that was posteriorly stained with silver nitrate (Bronzoni et al., 2005).

\subsection{Case and control definitions}

We analysed all dengue reports that were recorded between epidemiological weeks 36/2012 and 19/2013 in the study area. Data was recovered from the Information System on Diseases of Compulsory Declaration (SINAN). We defined as cases suspected infections that 


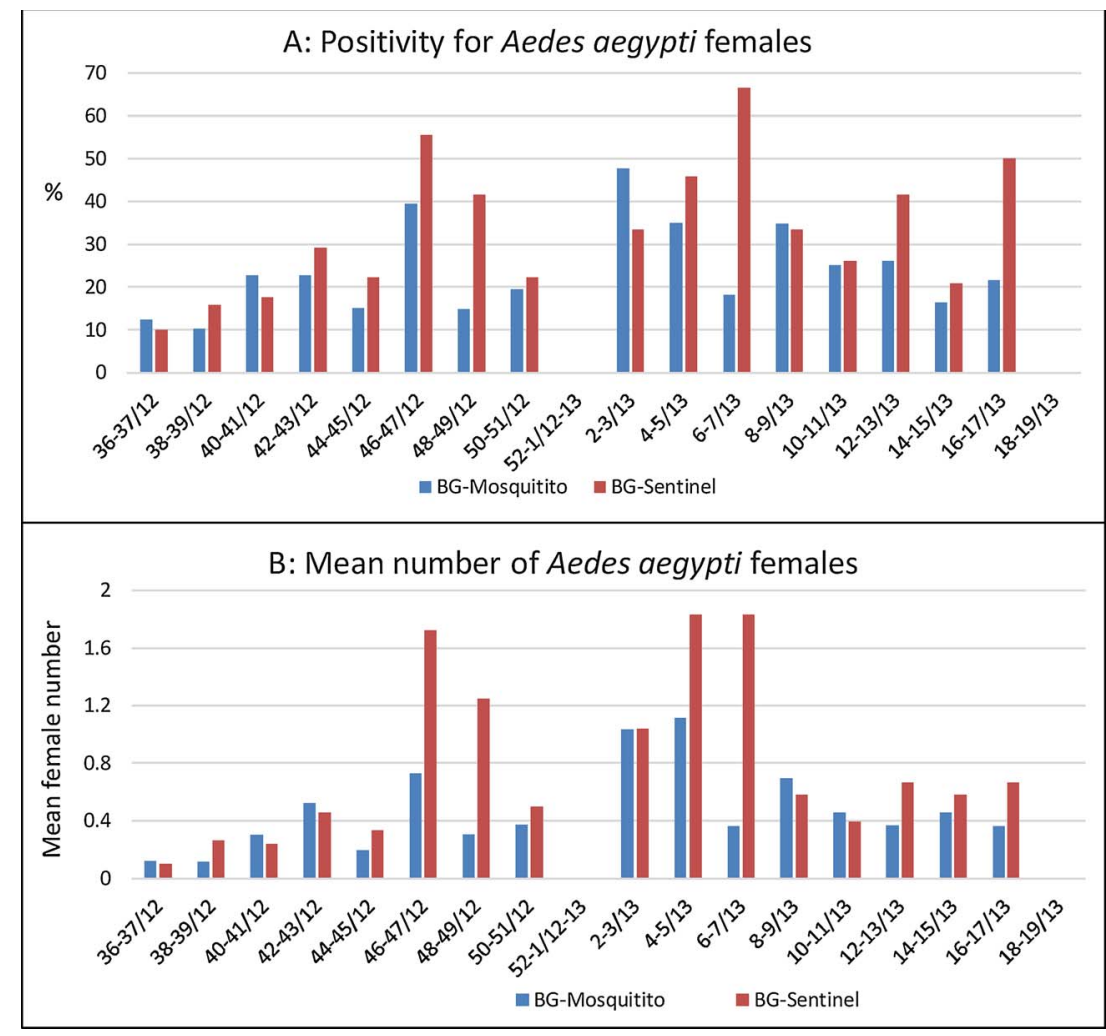

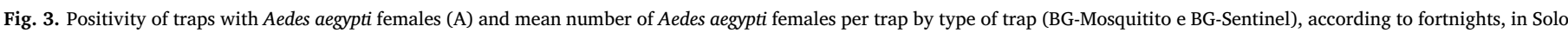
Sagrado neighborhood, São José do Rio Preto, São Paulo State, Brazil. Collections were performed between epidemiological weeks 36 of 2012 and 19 of 2013.

were confirmed positive by molecular or serological assays from week $36 / 2012$ to $6 / 2013$. We had to change our definition of case from week $7 / 2013$ onwards, when the Secretary of Health of the State of São Paulo (CVE, 2012) declared an epidemic in São José do Rio Preto. Not only laboratory confirmed infections but suspected dengue reports that matched clinical and epidemiological criteria were also considered cases. The inclusion of clinical and epidemiological criteria as a potential real dengue infection occurs when a given municipality is considered epidemic for the virus in the state of São Paulo. This measure is to avoid overloading reference laboratories of the state (CVE, 2012). We defined as controls suspected dengue cases that were tested negative for dengue by molecular or serological assays.

\subsection{Geocoding of the locations}

We created databases containing trap information and dengue cases with Microsoft Excel. The trap database gathered data such as: address, date of installation, date of collection, number of specimens, species of mosquitos, and result of molecular analysis. The dengue case database included addresses of dengue reports, date of onset of symptoms, type and results of laboratory analysis. We used TerraView (INPE, 2013) to geocode the addresses of these databases.

\subsection{Entomological index}

These are the guidelines we followed to build the entomological index for adult Ae. aegypti: i. Number of trapped females of Ae. aegypti; ii. The assumption that a trap installed in a house would represent the number of females in the household and in another eight residences surrounding the trap. The 150-200 m flight range of the mosquito and urban settings of the study area favor the assumption; iii. Point collections represent the average number of females over the period of a week, not only $24 \mathrm{~h}$; iv. The index represents the number of female mosquitos per 100 households, just like the Breteau Index.
The Number of adult Ae. aegypti females (NAF) in 100 residences over one week, under the circumstances of our study, is calculated as follows:

$\mathrm{NAF}=\frac{\text { Number of adult Aedes aegypti females } \times 7}{9} \times 100$

NAF was calculated biweekly instead of weekly. We have decided to attenuate eventual bias due to poor collections induced by occasional issues with trap installation on holidays and rainy days, which hindered trap installation on one or both installation days; closed properties; refusals to comply with the installation due to withdrawn consent for installation.

The number of adult Ae. aegypti females per each trap was calculated using $i$. the average number of collected females during both weeks of a fortnight, when information from both weeks was available; or ii. the number of females in one week, when the trap was installed in only one week of the fortnight. 7 and 9 are, respectively, the number of days in a week and the assumption that nine houses would present the same number of Ae. aegypti females.

\subsection{Vector control measures}

The Municipal Team for Dengue Control (EMCD) in São José do Rio Preto, and the Agency for the Control of Endemic Diseases (SUCEN) performed vector control activities in the area during the study period: i. House-to-house sweeps, which are routine activities performed on all properties to eliminate vector breeding areas; ii. Emergency sweeps, which are focused on areas with a high level of infestation; iii. Elimination of breeding sites, which is the mechanical removal of areas where females can lay their eggs; iv. fogging, used in areas with active dispersal of virus to eliminate possibly infected adult mosquitoes. We obtained qualitative data (i to iii) and quantitative data (iv) performed in the area during the study period. These data were obtained from SISAWEB, an online system provided by SUCEN (SUCEN, 2017) 


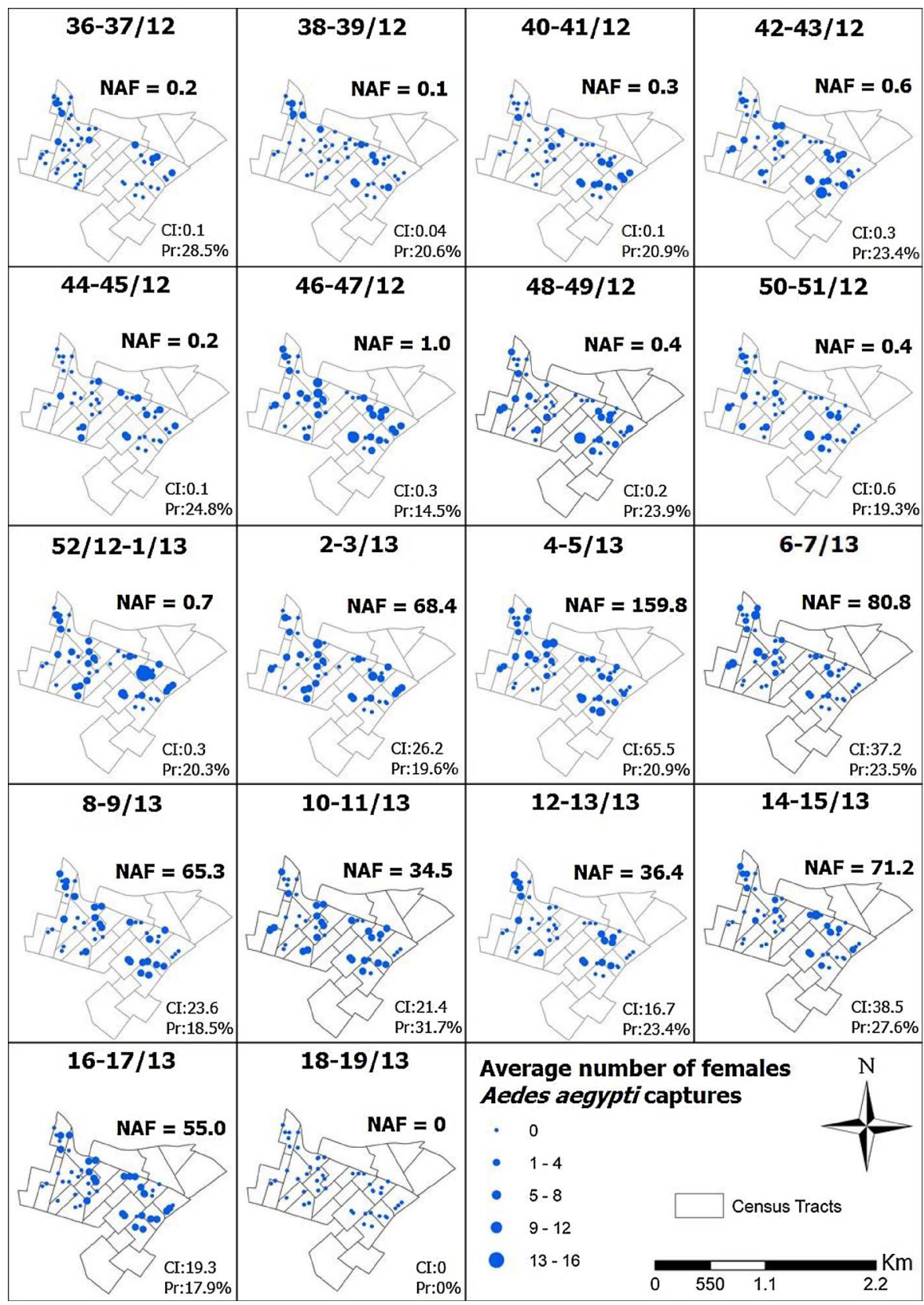

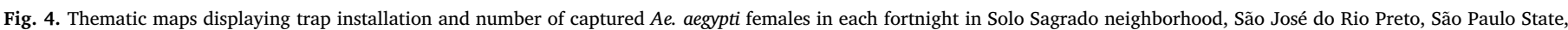
Brazil. Traps were installed between epidemiological weeks 36 of 2012 and 19 of 2013 . CI = Confidence Interval; Pr $=$ Precision. NAF represents the global NAF.

\subsection{Data analysis}

We used both primary data (number of females and adult Ae. aegypti mosquitoes) and secondary data (dengue cases) to validate NAF as an entomological index capable to identify areas at risk for dengue. Numbers of females and dengue cases were grouped according to their fortnight distribution. At this point, we paired NAF and dengue cases reported during the same fortnight. We chose to analyse data according to fortnight in order to increase the power of the study (i.e., to obtain a higher number of positive and negative dengue cases) and to avoid the aforementioned bias.

We used an ordinary kriging technique to build entomological index maps of NAF. We performed a statistical interpolation of data using geoR package of R statistical software (R Core Team, 2017). Weight was defined using a semivariogram estimated from core parameters, contribution and amplitude (Ribeiro and Diggle, 2001). We built maps with interpolated NAF values that were organized by fortnight during the study period.

We analysed risk of dengue fever in the neighborhood using a model capable of describing both spatial pattern of transmission as well as areas with higher or lower spatial risk. We tested the hypothesis of the existence of a correlation between NAF and dengue occurrence using a spatial case-control design and a generalized additive model with a level of significance of $5 \%$ (Hastie and Tibshirani, 1990). The cases and controls used in this model were defined above (Section 2.4). Although Ae. aegypti females were captured throughout the study period, our validation analysis considered only the period between epidemiological weeks $4 / 2013$ and $17 / 2013$, since most of confirmed cases of dengue in residents of the area were from this period.

The Epigam package of the $\mathrm{R}$ statistical software ( $\mathrm{R}$ Core Team, 2017) was used for the analysis. Initially, only the location of positive and negative dengue fever cases was considered. Geographical coordinates of these cases were treated as independent variables for the occurrence of the disease. In the subsequent step, NAF was introduced 


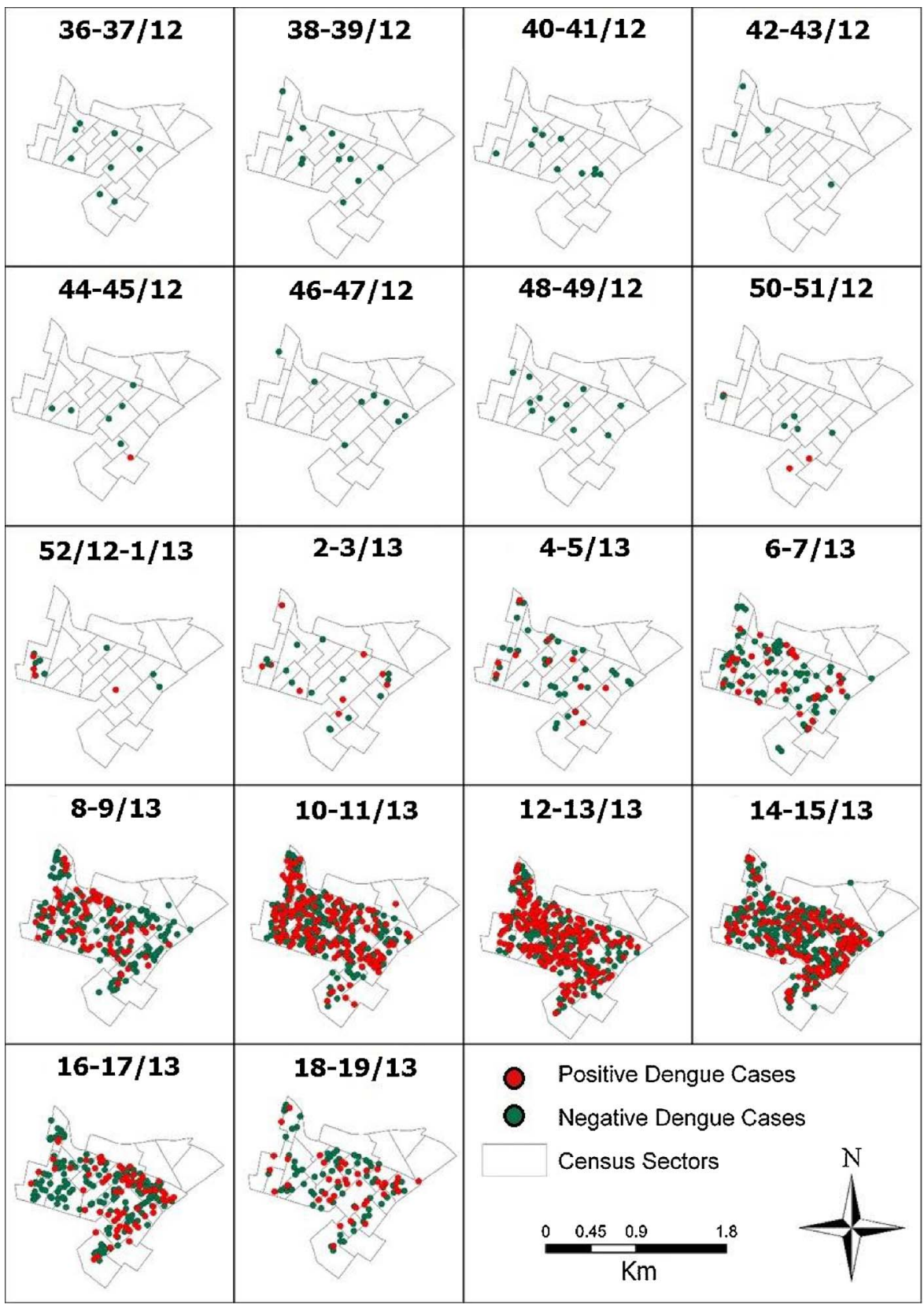

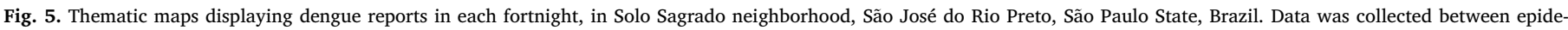
miological weeks 36 of 2012 and 19 of 2013.

in the model as a covariate, maintaining the representative variables of the coordinates. The final step was to calculate the odds ratio (OR) of each fortnight for the occurrence of dengue fever associated with oneunit variations in NAF adjusted for geographical coordinates of the locations where cases were reported (Barbosa et al., 2014; Fares et al., 2015). We considered 0.05 as the significance level of our study and constructed thematic maps displaying the risk of dengue occurrence by fortnight.

We wanted to analyse how control measures used in the area affect NAF and dengue occurrence. Data for control measures were only available for the whole study area, so we were not able to geocode addresses and include them in the model. Therefore, we performed a qualitative evaluation of the role of control measures in NAF and dengue cases.

We compared the costs for NAF and BI in terms of human resources. The estimative of human resources necessary to calculate BI was based on parameters established by Ae. aegypti Entomological Surveillance
Manual (SUCEN, 1997). We used guidelines for areas that are similar in size to our study site. The following conditions were fulfilled: a sample size of 500 properties, with approximately $50 \%$ precision of the BI value; the ability of each field agent to visit 20 properties per day; and the need for additional human resources (SUCEN, 1997). The human resources necessary to measure NAF were made based on the personnel and time required for this study.

\subsection{Ethics}

This study was approved by the Internal Review Board from the Medical School of São José do Rio Preto (FAMERP) (protocol \#02078812.8.0000.5415). Homeowners who had traps installed on their properties signed an informed consent form. 


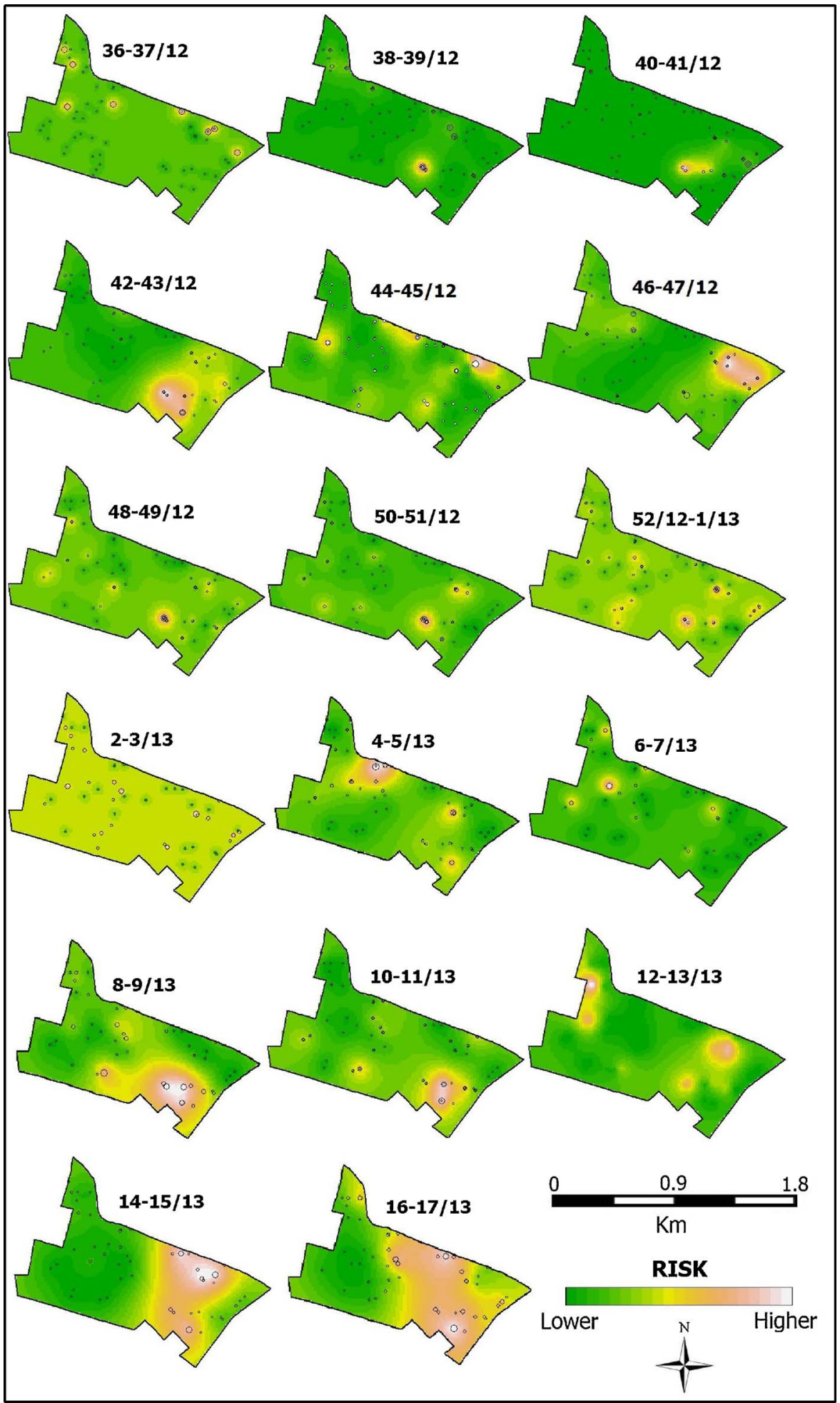

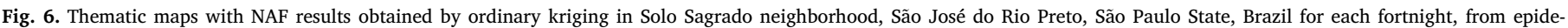
miological weeks 36 of 2012 to 19 of 2013 .

\section{Results}

We were able to install 1572 traps during the study period. The possible number of installations was 2232, which corresponds to 31 traps twice a week for 36 weeks. However, we had 660 losses and 40 trap location changes. The more frequent reason for losses were inaccessible houses, days off (mainly holidays) and rainy days. The majority of changes $(60 \%)$ of residences occurred in the initial five weeks of our study.

Our traps captured 6024 mosquitoes of Aedes and Culex genera. They trapped 1333 Ae. aegypti mosquitoes (536 males and 797 females), and 4691 Culex sp. (3325 males and 1366 females). Ae. aegypti specimens were pooled in 893 tubes that were tested for the presence of DENV. DENV-4 was found in 25 pools (2.8\%), in which 19 were females and 6 were males. Fig. 3 presents the positivity of traps for Ae. aegypti females and the mean number of Ae. aegypti females per trap by type of 
Table 1

Odds ratio values and their respective $p$-values by fortnight (between epidemiological weeks 4 and 17 of 2013), in Solo Sagrado neighborhood, São José do Rio Preto, São Paulo State, Brazil

\begin{tabular}{llll}
\hline Fortnight & \multicolumn{2}{l}{ Odds ratio } & $p$-value \\
\cline { 2 - 3 } & Estimative & $95 \%$ confidence intervals & \\
\hline $4 \_5$ & 1.074 & $1.036-1.114$ & 0.0003 \\
$6 \_7$ & 1.004 & $1-1.008$ & 0.0796 \\
$8 \_9$ & 1.017 & $1.011-1.023$ & 0.0000 \\
$10 \_11$ & 1.006 & $0.996-1.016$ & 0.2084 \\
$12 \_13$ & 0.999 & $0.996-1.003$ & 0.7392 \\
$14 \_15$ & 0.993 & $0.985-1$ & 0.0473 \\
$16 \_17$ & 1.015 & $1.007-1.023$ & 0.0002 \\
\hline
\end{tabular}

trap and fortnights.

No mosquito collection occurred in the fortnight that corresponds to epidemiological weeks 52/2012 and 1/2013, which corresponds to Christmas holidays. All installed traps were negative in the fortnight 18-19/2013. As expected, both types of traps presented similar positivity. The only exceptions occurred in fortnights 48-49/2012, 6-7/ 2013, and 16-17/2013. The mean number of females between traps suffered variations in fortnights 48-49/2012, 4-5/2013, and 6-7/2013.

Over 2500 suspected dengue cases were reported in the study area. We enrolled 1137 as cases. There were 820 reports that tested positive for DENV (72.1\%) and 317 that matched clinical epidemiological criteria (27.9\%). When São José do Rio Preto was not officially in a dengue epidemic, all dengue reports prior to epidemiological week 7/ 2013 ( $n=40$ ) were confirmed by laboratorial methods. We enrolled 1450 reports that tested negative for DENV as controls. Thematic maps display trap locations and numbers of Ae. aegypti females in each fortnight (Fig. 4) as well as points where dengue fever was reported. (Fig. 5).

Only negative cases were reported during the initial fortnights. The first positive dengue case was detected during fortnight 44-45/2012, and the number of positive cases peaked during fortnights 10-11 and 12-13/2013 (Fig. 5). The increase in dengue fever cases occurred in parallel with the increase in number of Ae. aegypti females (Figs. 4 and 5). However, there are exceptions, including fortnights 12-13 and 14-15 in particular, when dengue cases peaked. Meanwhile, there was a decrease in females when compared to the previous fortnight (10-11). Ordinary kriging at different levels of spatial aggregation, ranging from local to global, showed an important local variation in the entomological index in the study area in different fortnights (Fig. 6). Subareas presented variability in vector infestation.

Odds ratio and their respective $p$-values for NAF values and dengue occurrence, adjusted for the coordinates of the cases and controls, are presented in Table 1 . NAF was positively and significantly associated with dengue fever cases in three (4-5, 8-9, and 16-17) of the seven fortnights analysed; positively and marginally associated in one of the fortnights (6-7); not associated in two of the fortnights (10-11 and 12-13); and negatively and significantly associated in one of the fortnights (14-15).
If we consider OR as a measure of relative risk, the value 1.074 in fortnight 4-5 represents a $7.4 \%$ increase in the risk of dengue occurrence for every one-unit increase in NAF (that is, in the number of adult Ae. aegypti females in 100 houses during a week). The OR value of 0.993 during fortnight $14-15$ expresses a $0.7 \%$ decrease in the risk of dengue occurrence when there is a one-unit increase in the NAF.

Table 2 shows the control measures performed by the EMCD and SUCEN for the study area between weeks 4 and 17 . House-to-house and emergency sweeps were performed during the entire study period, and elimination of breeding sites was usually followed by fogging activities.

The information in Tables 1 and 2 combined with data in Figs. 3 and 4 suggest that the fogging activity performed in week 5 and 10 decreased the level of significance of dengue cases and NAF respectively in fortnight 6-7 and 10-11. Fogging activities performed in weeks 13-15 revealed its effect on the significance of OR. This feature was evident when the highest incidences were reported in week 14 , when 3206 properties were sprayed. Fogging activities led to a non-significant OR value below 1 in weeks $12-13$ and a significant value below 1 in weeks 14-15. The absence of fogging in weeks 16 and 17 confirms these results, as correlation between dengue occurrence and NAF became positive and significant again in weeks 16-17.

NAF (upper portion) and spatial risk of dengue occurrence (lower portion) can be seen in Fig. 7. Maps show that areas with high NAFs and high spatial risk of dengue overlap, particularly on fortnights in which OR values were above 1 and were significant.

Based on established parameters, five field agents would be necessary to cover the study area over the course of a week to measure BI. These agents would have to search 500 properties, which would result in 20 residence visits in one day per agent, over 5 days. Additional human resources, such as a driver and a supervisor, are also necessary. To collect data for NAF over one week, one field agent and one driver were necessary to install and collect an average of 50 traps. Comparatively, NAF presented lower human requirement than BI, using $71,5 \%$ less human resources to cover the same area.

\section{Discussion}

Our analysis indicates that increases in dengue cases occurred in parallel with the increase in numbers of Ae. aegypti females. Our entomological index correlates positively with dengue incidence, particularly during intervals when vector control measures were applied less intensively. Our index operational costs were lower than those of BI: NAF used 71,5\% less human resources necessary to measure BI.

NAF seems adequate for predicting dengue occurrence. Our data clearly shows that the increase in dengue cases occurred concomitantly with the increase in numbers of Ae. aegypti females. Entomological indices based on the adult form of the vector seem to be important tools for predicting the risk of dengue fever (Wijayanti et al., 2016). Attaway et al. (2016) identified areas at risk of dengue occurrence in Africa. They state that many variables should be taken into account when spatial analysis techniques are employed. Our results suggest that NAF identifies areas of higher risk of dengue occurrence. Additionally, NAF may serve as a new surveillance and control tool to detect and restrain

Table 2

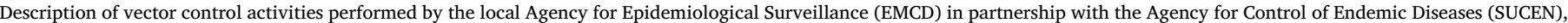
between epidemiological weeks 4 and 17 of 2013), in Solo Sagrado neighborhood, São José do Rio Preto, São Paulo State, Brazil. Source: SINAN (2017). Done (D) or not done (ND).

\begin{tabular}{|c|c|c|c|c|c|c|c|c|c|c|c|c|c|c|}
\hline \multirow[t]{2}{*}{ Method/Epidemiological week (2013) } & \multicolumn{14}{|c|}{ Control activities } \\
\hline & 4 & 5 & 6 & 7 & 8 & 9 & 10 & 11 & 12 & 13 & 14 & 15 & 16 & 17 \\
\hline Fogging & ND & $\mathrm{D}$ & ND & $\mathrm{ND}$ & $\mathrm{ND}$ & ND & $\mathrm{D}$ & $\mathrm{ND}$ & $\mathrm{ND}$ & $\mathrm{D}$ & $\mathrm{D}$ & $\mathrm{D}$ & ND & ND \\
\hline House-to-house sweeps & $\mathrm{D}$ & $\mathrm{D}$ & $\mathrm{D}$ & $\mathrm{D}$ & $\mathrm{D}$ & $\mathrm{D}$ & $\mathrm{D}$ & $\mathrm{D}$ & $\mathrm{D}$ & $\mathrm{D}$ & $\mathrm{D}$ & $\mathrm{D}$ & $\mathrm{D}$ & $\mathrm{D}$ \\
\hline Emergency sweeps & ND & ND & $\mathrm{D}$ & $\mathrm{D}$ & ND & $\mathrm{D}$ & ND & $\mathrm{D}$ & $\mathrm{D}$ & $\mathrm{D}$ & $\mathrm{D}$ & $\mathrm{D}$ & $\mathrm{D}$ & $\mathrm{D}$ \\
\hline Elimination of breeding sites & $\mathrm{D}$ & $\mathrm{D}$ & ND & ND & ND & ND & ND & ND & ND & $\mathrm{D}$ & $\mathrm{D}$ & $\mathrm{D}$ & $\mathrm{D}$ & $\mathrm{D}$ \\
\hline
\end{tabular}




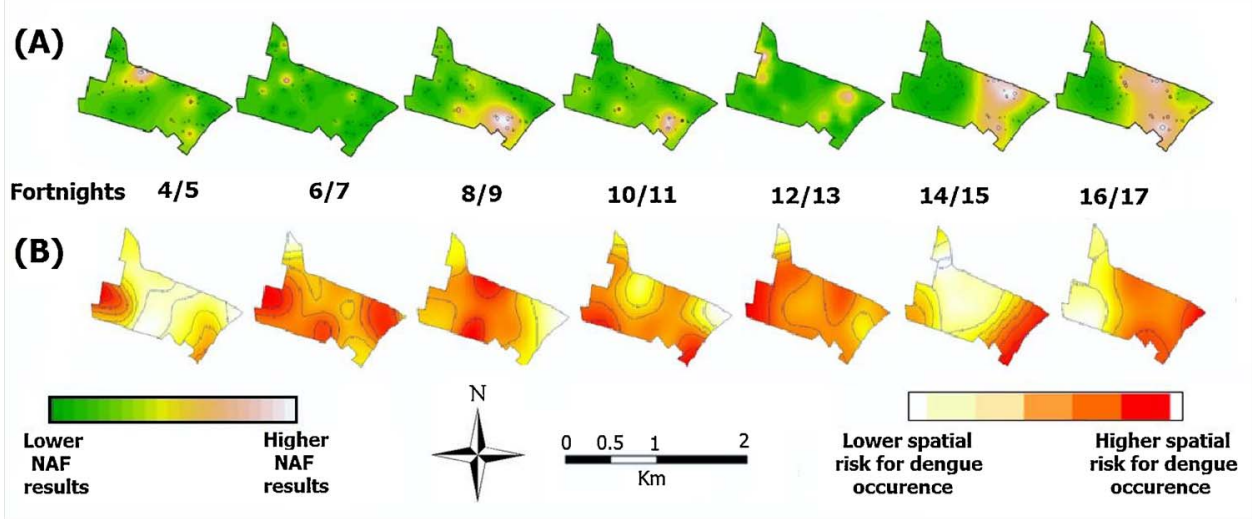

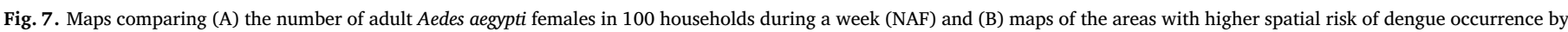
fortnight, in Solo Sagrado neighborhood, São José do Rio Preto, São Paulo State, Brazil, from epidemiological weeks 36 of 2012 to 19 of 2013.

viruses transmitted by Ae. aegypti and other vectors.

The validation of NAF as an index to measure risk of disease occurred simultaneously with the introduction of DENV-4 in São José do Rio Preto (Colombo et al., 2016; Rocco et al., 2012). DENV-4 was the only serotype detected in our mosquitoes, which is an indication this was the main serotype causing dengue fever, at least in the study area. A population completely or partially susceptible to a specific serotype combined with its prevalence is adequate to evaluate a new entomological index and its correlation with disease occurrence. It minimizes the bias of the population immunity to the specific serotype (Chiaravalloti-Neto et al., 2015). Thus, we were able to evaluate an entomological method that can predict risk areas for dengue in a susceptible population.

There are currently a few DENV vaccines being tested and/or sold in various countries (Achee et al., 2015). However, for the effective control of the disease, vector control and surveillance are still required. There is a particular need for tools capable of predicting epidemics (Achee et al., 2015). Therefore, it is necessary to search for entomological indices capable of measuring risk. It is also important to consider that the only current solution for zika and chikungunya infections, is vector surveillance and control (Rodriguez-Morales et al., 2016; Ruiz-Moreno, 2016). The most commonly used methods for entomological surveillance of Ae. aegypti are based only in mosquito larvae (Barbosa et al., 2010; Wijayanti et al., 2016). On the other hand, NAF is based on adult females, presents a superior performance and a lower operational cost. Comparatively, NAF demanded 71,5\% less human resources to be constructed when compared to BI.

Barbosa et al. (2010) suggested that eggs from oviposition traps could be used as an index to determine areas with higher risks for epidemics. However, the authors also suggested that this methodology is more adequate for situations in which there is substantial mosquito production. The number of eggs collected in oviposition traps has the biasing effect related to the increased or decreased supply of vector breeding areas. This effect does not bias the indices calculated based on adult traps. In addition, traps used in our study were capable of collecting other mosquito species, such as Culex $s p$, which is the vector of West Nile, Saint Louis and Japanese encephalitis viruses, and filarial worms. For this reason, our index could be adapted to predict epidemics caused by other mosquito species.

We described the vertical transmission of DENV-4 in pools of male mosquitos. This phenomenon may also explain maintenance of the virus in interepidemic periods. DENV may be maintained by low number of human infections and vertical transmission. Angel and Joshi (2008) and Le Goff et al. (2011) worked with immature forms of the Aedes mosquito and suggested that these mosquitoes function as reservoirs for DENV during periods of the year that are not favorable to human DENV transmission. Martins et al. (2012) studied DENV transmission in
Fortaleza, Ceará State, Brazil, and observed vertical transmission in naturally infected mosquitos. However, Zeidler et al. (2008) stated that vertical transmission in Ae. aegypti does not occur with a frequency that could determine the persistence of the virus in urban environments and the persistence of the virus between epidemics could not be attributed to vertical transmission of DENV.

Despite the potential applicability of our index, we had to face limitations. The first, and perhaps most important, is the lack of detailed information on vector control measures, given its potential to bias NAF and dengue occurrence, particularly fogging that has the strongest potential to affect the data, because it is designed to eliminate adult females in areas of viral transmission. As a result, control measures were evaluated qualitatively in our model. We founded that NAF was not associated in two of the fortnights (10-11 and 12-13), and was significantly negatively associated in one of the fortnights (14-15). The spread of fogging may have influenced our results. Thus, it was not possible to observe a strong positive correlation in all fortnights. A second limitation involves issues with trap installation (holidays, rainy days, closed properties, and well as refusals by homeowners) and types of traps (BG Sentinel and BG Mosquitito). This limitation is relieved by the fact that the positivity and mean number of females of the two traps were similar in the majority of fortnights and grouping the data in fortnights.

Finally, other important limitation was to use clinical and epidemiological criteria and laboratory assays to confirm dengue cases from week 7/2013 onwards, which could cause misclassification errors. However, it is possible to state that the OR obtained for fortnight 4-5/ 2013 was not affected by this misclassification error, since all cases and controls of this fortnight were confirmed by laboratory assays.

The main argument for the use of the clinical and epidemiological criteria during a situation of strong dengue transmission refers to the increase in dengue prevalence. Consequently, the probability that a suspected dengue case tends to be a real positive dengue case also increases, since the positive predictive value increases (Fletcher et al., 2014; Chiaravalloti-Neto et al., 2015). Besides, more than $70 \%$ of the positive cases and all negative cases were confirmed by laboratory assays, which minimizes the limitation to the point where the association found between the proposed entomological index and occurrence of dengue in fortnights 6-7/2013 onwards are also valid.

Despite these limitations, we believe that it was possible to adequately test the hypothesis of the study and to validate the use of NAF as an entomological index for measuring risk of dengue fever. We wish to highlight the role of spatial analysis tools to reach the objectives of this study, especially kriging and statistical interpolation. These tools allowed for the spatial representation of NAF on a larger scale than the size of the study area, while stratifying the risk of infection occurrence at different levels of spatial aggregation. Furthermore, it was an 
important step towards understanding relevant parameters related to dengue transmission in Brazil. Additional studies should be performed to evaluate the use of the methodology described here in various locations and other infection scenarios.

\section{Conclusions}

The number of adult Ae. aegypti females (NAF) index was adequate to predict the risk of dengue fever occurrence. We produced a risk index that could be used at various levels of spatial aggregation (i.e., for the whole study area, or for sub-areas such as street blocks) by employing spatial analysis techniques and the number of adult Ae. aegypti females. NAF was implemented with lower operational costs than those of the Breteau Index. As Ae. aegypti also transmits other pathogens, NAF can also be tested as an index capable to predict the risk for other arbovirus outbreaks. NAF has the potential to be used by public health authorities to make decisions involving use of control measures for areas of higher risk of dengue infection. It must be validated in other scenarios before it can be used routinely.

\section{Fundings}

We received grants from Fundação de Amparo à Pesquisa do Estado de São Paulo - FAPESP (Grant 2013/21719-3 to MLN and FCN) and Conselho Nacional de Desenvolvimento Cientifico e Tecnologico CNPq - (research fellows for MLN and FCN).

\section{References}

Achee, N.L., Gould, F., Perkins, T.A., Reiner Jr., R.C., Morrison, A.C., Ritchie, S.A., et al., 2015. A critical assessment of vector control for dengue prevention. PLoS Negl. Trop. Dis. 9 (5), e0003655.

Angel, B., Joshi, V., 2008. Distribution and seasonality of vertically transmitted dengue viruses in Aedes mosquitoes in arid and semi-arid areas of Rajasthan, India. J. Vector Borne Dis. 45 (1), 56.

Attaway, D.F., Jacobsen, K.H., Falconer, A., Manca, G., Waters, N.M., 2016. Risk analysis for dengue suitability in Africa using the ArcGIS predictive analysis tools (PA tools). Acta Trop. 158, 248-257.

Barbosa, A.A.C., Fávaro, E.A., Mondini, A., Dibo, M.R., Chiaravalloti Neto, F., 2010. Evaluation of oviposition traps as an entomological surveillance method for Aedes aegypti (Diptera, Culicidae). Rev. Bras. Entomol. 54 (2), 328-331.

Barbosa, G.L., Donalísio, M.R., Stephan, C., Lourenço, R.W., Andrade, V.R., de Brito Arduino, M., de Lima, V.L.C., 2014. Spatial distribution of the risk of dengue and the entomological indicators in Sumaré, State of São Paulo, Brazil. PLoS Negl. Trop. Dis. 8 (5), e2873.

Barrera, R., 2016. Recommendations for the surveillance of Aedes aegypti. Biomédica 36 (3), 454-462.

Bowman, L.R., Runge-Ranzinger, S., McCall, P.J., 2014. Assessing the relationship between vector indices and dengue transmission: a systematic review of the evidence. PLoS Negl. Trop. Dis. 8 (5), e2848.

Bronzoni, R.V., Baleotti, F.G., Nogueira, R.M.R., Nunes, M., Figueiredo, L.T.M., 2005. Duplex reverse transcription-PCR followed by nested PCR assays for detection and identification of Brazilian alphaviruses and flaviviruses. J. Clin. Microbiol. 43 (2), 696-702.

CPTEC/INPE - Centro de Previsão do Tempo e Estudos Climáticos - Ministério de Ciência e Tecnologia. Available from http://www.cptec.inpe.br.

CVE - Centro de Vigilância Epidemiológica "Prof. Alexandre Vranjac". Guia de vigilância epidemiológica (2012). Available from //ftp.cve.saude.sp.gov.br/doc_tec/outros/ CVE12 GUIA_VE_ATUALIZADO.pdf.

CVE - Centro de Vigilância Epidemiológica "Prof. Alexandre Vranjac" (2016) - Available from http://portal.saude.sp.gov.br/cve-centro-de-vigilancia-epidemiologica-prof.alexandre-vranjac/areas-de-vigilancia/doencas-de-transmissao-por-vetores-ezoonoses/agravos/dengue/.

CVE - Centro de Vigilância Epidemiológica "Prof. Alexandre Vranjac" (2018) - Available from http://portal.saude.sp.gov.br/resources/cve-centro-de-vigilanciaepidemiologica/areas-de-vigilancia/doencas-de-transmissao-por-vetores-e-zoonoses/ dados/dengue/dengue17 import autoc_res.htm.

Campbell, L.P., Luther, C., Moo-Llanes, D., Ramsey, J.M., Danis-Lozano, R., Peterson, A.T., 2015. Climate change influences on global distributions of dengue and chikungunya virus vectors. Phil. Trans. R. Soc. B 370 (1665), 20140135.

Chen, L.H., Wilson, M.E., 2010. Dengue and chikungunya infections in travelers. Curr. Opin. Infect. Dis. 23 (5), 438-444.

Chiaravalloti-Neto, F., Pereira, M., Fávaro, E.A., Dibo, M.R., Mondini, A., RodriguesJunior, A.L., et al., 2015. Assessment of the relationship between entomologic indicators of Aedes aegypti and the epidemic occurrence of dengue virus 3 in a susceptible population, São José do Rio Preto, São Paulo, Brazil. Acta Trop. 142, 167-177.
Coelho, G.E., 2012. Challenges in the control of Aedes aegypti. Rev. Inst. Med. Trop. São Paulo 54, 13-14.

Colombo, T.E., Vedovello, D., Mondini, A., Reis, A.F.N., Cury, A.A.F., Oliveira, F.H.D., et al., 2013. Co-infection of dengue virus by serotypes 1 and 4 in patient from medium sized city from Brazil. Rev. Inst. Med. Trop. São Paulo 55 (4), 275-281.

Colombo, T.E., Vedovello, D., Pacca-Mazaro, C.C., Mondini, A., Araújo, J.P., Cabrera, E. et al., 2016. Dengue virus surveillance: detection of DENV-4 in the city of Súo Josã do Rio Preto, SP, Brazil. Acta Trop. 164, 84-89.

Consoli, R.A., Oliveira, R.L.D., 1994. Principais mosquitos de importância sanitária no Brasil. Editora Fiocruz.

Estofolete, C.F., Terzian, A.C.B., Parreira, R., Esteves, A., Hardman, L., Greque, G.V., Nogueira, M.L., 2016. Clinical and laboratory profile of Zika virus infection in dengue suspected patients: a case series. J. Clin. Virol. 81, 25-30.

Fares, R.C., Souza, K.P., Añez, G., Rios, M., 2015. Epidemiological scenario of dengue in Brazil. BioMed Res. Int. 2015.

Figueiredo, R.M.P.D., Mourão, M.P.G., Abi-Abib, Y.E.C., Oliveira, C.M.D., Roque, R, Azara, T.D., et al., 2013. Identification of dengue viruses in naturally infected Aedes aegypti females captured with BioGents (BG)-Sentinel traps in Manaus, Amazonas, Brazil. Rev. Soc. Bras. Med. Trop. 46 (2), 221-222.

Fletcher, R., Fletcher, S.W., Fletcher, G.S., 2014. Clinical Epidemiology. Lippincott Wlliams \& Wilkins, Baltimore.

Focks, D.A., Brenner, R.J., Hayes, J., Daniels, E., 2000. Transmission thresholds for dengue in terms of Aedes aegypti pupae per person with discussion of their utility in source reduction efforts. Am. J. Trop. Med. Hyg. 62 (1), 11-18.

Focks, D.A., 2004. A Review of Entomological Sampling Methods and Indicators for Dengue Vectors.

Forattini, O.P., 2002. Culicidologia médica: Identificação, Biologia, Epidemiologia, vol. 2 EDUSP.

Gomes, A.D.C., 1998. Medidas dos níveis de infestação urbana para Aedes (Stegomyia) aegypti e Aedes (Stegomyia) albopictus em programa de vigilância entomológica. Inf. Epidemiol. SUS 7 (3), 49-57.

Hapairai, L.K., Joseph, H., Sang, M.A.C., Melrose, W., Ritchie, S.A., Burkot, T.R., et al., 2013. Field evaluation of selected traps and lures for monitoring the filarial and arbovirus vector, Aedes polynesiensis (Diptera: Culicidae), in French Polynesia. J. Med. Entomol. 50 (4), 731-739.

Hastie, T., Tibshirani, R., 1990. Generalized Additive Models. John Wiley Sons, Inc.

Higa, Y., 2011. Dengue vectors and their spatial distribution. Trop. Med. Health 39 (Suppl. 4), S17-S27.

Honório, N.A., Silva, W.C., Leite, P.J., Gonçalves, J.M., Lounibos, L.P., Lourenço-deOliveira, R., 2003. Dispersal of Aedes aegypti and Aedes albopictus (Diptera: Culicidae) in an Urban Endemic Dengue Area in the State of Rio de Janeiro, Brazil. Mem. Inst. Oswaldo Cruz 98 (2), 191-198.

IBGE - Instituto Brasileiro de Geografia e Estatística -Available from http://www. cidades.ibge.gov.br/xtras/perfil.php?lang $=\&$ codmun $=354980 \&$ search $=$ sao-paulo $\% 7$ Csao-jose-do-rio-preto.

INPE - Instituto de Pesquisas Espaciais (2013). TerraView 4.2.2. Available from http:// www.dpi.inpe.br/terraview4.2.2.

Lau, K.W., Chen, C., Lee, H., Izzul, A.A., Asri-Isa, M., Zulfadli, M., Sofian-Azirun, M., 2013. Vertical distribution of Aedes mosquitoes in multiple storey buildings in Selangor and Kuala Lumpur, Malaysia. Trop. Biomed. 30 (1), 36-45.

Le Goff, G., Revollo, J., Guerra, M., Cruz, M., Simon, Z.B., Roca, Y., et al., 2011. Natural vertical transmission of dengue viruses by Aedes aegypti in Bolivia. Parasite: J. Soc. Franç. Parasitol. 18 (3), 277.

MS - Ministério da Saúde do Brasil. Guia de Vigilância em Saúde (2014) Volume Único. Available from http://bvsms.saude.gov.br/bvs/publicacoes/guia vigilancia epidemiologica_7ed.pdf.

MS - Ministério da Saúde do Brasil (2016) - Available from http://portalsaude.saude gov.br.

Machado, D.C., Mondini, A., dos Santos Santana, V., Yonamine, P.T.K., Neto, F.C., de Andrade Zanotto, P.M., Nogueira, M.L., 2012. First identification of Culex flavivirus (Flaviviridae) in Brazil. Intervirology 55 (6), 475-483.

Maciel-de-Freitas, R., Firas, Á.E., Lourenço-de-Oliveira, R., 2006. Field evaluation of effectiveness of the BG-Sentinel, a new trap for capturing adult Aedes aegypti (Diptera: Culicidae). Mem. Inst. Oswaldo Cruz 101 (3), 321-325.

Maciel-de-Freitas, R., Peres, R.C., Alves, F., Brandolini, M.B., 2008. Mosquito traps designed to capture Aedes aegypti (Diptera: Culicidae) females: preliminary comparison of Adultrap, MosquiTRAP and backpack aspirator efficiency in a dengue-endemic area of Brazil. Mem. Inst. Oswaldo Cruz 103 (6), 602-605.

Martins, V.E.P., Alencar, C.H., Kamimura, M.T., de Carvalho Araujo, F.M., De Simone, S.G., Dutra, R.F., Guedes, M.I.F., 2012. Occurrence of natural vertical transmission of dengue- 2 and dengue- 3 viruses in Aedes aegypti and Aedes albopictus in Fortaleza, Ceará, Brazil. PLoS One 7 (7), e41386.

Mondini, A., de Moraes Bronzoni, R.V., Nunes, S.H.P., Neto, F.C., Massad, E., Alonso, W.J., et al., 2009. Spatio-temporal tracking and phylodynamics of an urban dengue 3 outbreak in Sao Paulo, Brazil. PLoS Negl. Trop. Dis. 3 (5), e448.

R Core Team, 2017. R: A Language and Environment for Statistical Computing. R Core Team, Vienna, Austria(Available from https://www.r-project.org/).

Reiter, P., Amador, M.A., Anderson, R.A., Clark, G.G., 1995. Dispersal of Aedes aegypti in an urban area after blood feeding as demonstrated by rubidium-marked eggs. Am. J. Trop. Med. Hyg. 52 (2), 177-179.

Ribeiro Jr., P.J., Diggle, P.J., 2001. geoR: a package for geostatistical analysis. R News 1 (2), 14-18.

Rocco, I.M., Silveira, V.R., Maeda, A.Y., Silva, S.J.D.S., Spenassatto, C., Bisordi, I., Suzuki, A., 2012. First isolation of dengue 4 in the state of São Paulo, Brazil, 2011. Rev. Inst. Med. Trop. São Paulo 54 (1), 49-51.

Rodriguez-Morales, A.J., Galindo-Marquez, M.L., García-Loaiza, C.J., Sabogal-Roman, J. 
A., Marin-Loaiza, S., Ayala, A.F., et al., 2016. Mapping Zika virus infection using geographical information systems in Tolima, Colombia, 2015-2016. F1000 Research, 5.

Ruiz-Moreno, D., 2016. Assessing Chikungunya risk in a metropolitan area of Argentina through satellite images and mathematical models. BMC Infect. Dis. 16 (1), 49.

SUCEN, 1997. Manual de Vigilância Entomológica de Aedes aegypti. Secretaria de Estado da Saúde de São Paulo, Governo do Estado de São Paulo.

SUCEN - Atividades de Vigilância e Controle de Dengue - Superintendência de Controle de Endemias - Secretaria de Saúde do Estado de São Paulo (2017) . Available from http://200.144.1.23/sisaweb.

SVS - Secretária de Vigilância em Saúde - Ministério da Saúde (2017). Boletim Epidemiológico - BEPA (2017) ISSN 2358-9450.

Souza, R.P., Rocco, I.M., Maeda, A.Y., Spenassatto, C., Bisordi, I., Suzuki, A., et al., 2011. Dengue virus type 4 phylogenetics in Brazil 2011: looking beyond the veil. PLoS Negl. Trop. Dis. 5 (12), e1439.

Steffler, L.M., Marteis, L.S., dos Santos, R.L.C., 2011. Fontes de informação sobre dengue e adoção de atitudes preventivas. Sci. Plena 7 (6).

WHO - World Health Organization, Special Programme for Research, Training in Tropica Diseases, World Health Organization. Department of Control of Neglected Tropical Diseases, World Health Organization. Epidemic, \& Pandemic Alert. (2009). Dengue: guidelines for diagnosis, treatment, prevention and control. World Health Organization.

Wijayanti, S.P., Sunaryo, S., Suprihatin, S., McFarlane, M., Rainey, S.M., Dietrich, I., et al., 2016. Dengue in Java, Indonesia: relevance of mosquito indices as risk predictors. PLoS Negl. Trop. Dis. 10 (3), e0004500.

Zayed, A., Awash, A.A., Esmail, M.A., Al-Mohamadi, H.A., Al-Salwai, M., Al-Jasari, A., et al., 2012. Detection of chikungunya virus in Aedes aegypti during 2011 outbreak in Al hodayda, Yemen. Acta Trop. 123 (1), 62-66.

Zeidler, J.D., Acosta, P.O.A., Barrêto, P.P., da Silva Cordeiro, J., 2008. Vírus dengue em larvas de Aedes aegypti e sua dinâmica de infestação, Roraima, Brasil. Rev. Saúde Públ. 42 (6), 986-991. 